REVISTA DE ESTUDIOS E INVESTIGACIÓN EN PSICOLOGÍA Y EDUCACIÓN

\title{
Inclusão de jovens e adultos com deficiência na educação pública do Ceará: uma incursão documental
}

\section{Inclusion of young people and adults with disability in the public education system of Ceará: a documentary foray}

\author{
Gerda Holanda (iD) https://orcid.org/0000-0001-5881-6238 \\ Faculdade de Psicologia e de Ciências da Educação, Universidade de Coimbra \\ https://www.uc.pt/fpce
}

Marcelino Pereira (DD https://orcid.org/0000-0002-1468-2124

Centro de Investigação em Neuropsicologia e Intervenção Cognitivo-Comportamental (CINEICC) e Faculdade de Psicologia e de Ciências da Educação, Universidade de Coimbra https://cineicc.uc.pt/ e https://www.uc.pt/fpce

Coimbra - Portugal 


\title{
Resumo
}

A inclusão de jovens e adultos com deficiência no sistema de educação pública do Brasil e a garantia de acesso a uma educação de qualidade e oportunidades para desenvolver suas habilidades é um desafio permanente. O objetivo deste estudo é compreender o processo de inclusão de jovens e adultos com deficiência na escola regular noturna do Ceará, a partir da análise de documentos que tratam da temática. A investigação constitue a primeira etapa ao macroprojeto de pesquisa intitulado Inclusão escolar de jovens e adultos com deficiência: experiências e possibilidades de participação plena na escola pública brasileira. O método de investigação baseia-se na pesquisa documental de fontes primárias, numa abordagem qualitativa, com foco nas políticas públicas que regem o processo de inclusão desses jovens. Os resultados evidenciam que a inclusão educacional envolve muito mais que a garantia de os alunos com deficiência estarem nas salas de aula regulares, pois a inclusão de jovens e adultos com deficiência implica uma ação conjunta que possibilite a construção de novos patamares educacionais. Indicam, também, que as políticas de inclusão do Estado vêm seguindo as diretrizes propostas na política nacional, em que a educação destas pessoas é um importante veículo de consolidação.

Palabras chave: educação inclusiva; pessoas com deficiência; ensino secundário; escola regular

\begin{abstract}
The inclusion of young people and adults with disability in the public education system in Brazil and ensuring them access to quality education and opportunities to develop their skills is an on-going challenge. The aim of this study is to examine the inclusion of young people and adults with disability in night school education in the state of Ceará, based on an analysis of primary sources on the subject. The study marks the first stage of a larger research project entitled Educational inclusion of young people and adults with disability: experiences and possibilities of full participation in the Brazilian public education system. The methodology used consisted of a qualitative documentary analysis of primary sources related to the public policies governing the inclusion of people with disability. The results show that educational inclusion involves much more than simply guaranteeing a seat in regular classrooms for students with disabilities and highlight the need for collective action to redefine educational outcomes. The results also show that state inclusion policies are in line with national policy, in which the education of these people is an important vehicle for consolidation.
\end{abstract}

Keywords: inclusive education; people with disability; secondary education; regular classrooms 
A Educação de Jovens e Adultos (EJA) é a modalidade brasileira de ensino que alberga, majoritariamente, os trabalhadores de baixa renda e os jovens e adultos em situação de exclusão e vulnerabilidade social, com defasagem idade-série, que necessitam concluir a Educação Básica num espaço educacional que se adeque ao seu contexto.

O Instituto Nacional de Estudos e Pesquisas Educacionais (INEP) (Brasil, 2020a) divulgou, através do Censo da Educação Básica, que foram matriculados 3.273.668 alunos na EJA, sendo a maioria $(62,2 \%)$ formada por jovens com menos de 30 anos. Esse contingente de alunos representa cerca de 7\% das matrículas totais efetivadas na Educação Básica, o que corresponde a três milhões de jovens em condição de marginalidade socioeconômica e desigualdade de oportunidade educativa, que têm na EJA uma alternativa de superação dessa condição de vulnerabilidade.

O Ceará, quarto estado da Região Nordeste do Brasil em extensão territorial, tem cerca de oito milhões e quinhentos mil habitantes e abriga, em suas salas de aula, na esfera pública municipal e estadual, cerca de um milhão e setecentos mil alunos (Brasil, 2020b). Na modalidade EJA, são mais de cento e setenta mil alunos e, do total de alunos, cerca de sessenta e quatro mil são identificados com deficiência, transtornos globais do desenvolvimento ou altas habilidades.

Esses jovens, que têm em comum a privação de oportunidades de aprendizagem na escola formal, bem como a privação de situações favoráveis de desenvolvimento humano, não podem mais ser ignorados, conforme estabelecido pela Organização das Nações Unidas (ONU) no Objetivo de Desenvolvimento Sustentável 4 (ODS 4) da Agenda 2030.

A defesa da educação inclusiva é uma premissa para a superação das condições de assistencialismo, segregação e exclusão pelas quais os alunos com deficiência foram historicamente submetidos. É, também, uma via de inserção social, que afirma de maneira mais categórica o ideário da escola como instrumento de equidade, entendendo-se a ideia de equidade como "o reordenamento dos mecanismos institucionais para estabelecer uma igualdade substancial que, no contexto do esquema social, é vantajosa para todos" (Rohling e Valle, 2016, p. 398) e que supõe o respeito às diferenças como condição para se adquirir a igualdade.

No entanto, incluir pressupõe muito mais que inserir e o sistema de ensino brasileiro tem se mostrado incapaz de proporcionar a esses alunos um ensino de qualidade, que lhes permita o desenvolvimento pleno de suas capacidades (Pletsch, 2014; Orrú, 2017), embora a legislação brasileira sinalize que a educação inclusiva no país "fundamenta-se em princípios constitucionais de vanguarda, alinhados aos mais avançados temas da atualidade, tais como o reconhecimento 
e a valorização das diferenças, a inserção incondicional de todos à educação de nível básico e superior, entre outros" (Mantoan e Santos, 2010, p. 21).

Esses princípios estão expressos na Constituição da República Federativa do Brasil (Brasil, 1988), que garantiu a inclusão em larga escala e extensiva a todos, sem distinção de origem, raça, sexo, cor, idade ou qualquer outro tipo de discriminação, mas sem deixar claro se, no âmbito educacional de pessoas com deficiência, a inclusão é pautada pelo modelo da integração escolar, onde "o aluno tem acesso às escolas por meio de um leque de possibilidades educacionais, que vai de inserção às salas de aula do ensino regular ao ensino em escolas especiais" ou pelo modelo da inclusão, cuja proposta alberga "um modo de organização do sistema educacional que considera as necessidades de todos os alunos, estruturado em função dessas necessidades" (Mantoan, 2015, p. 22-23).

A discussão avança e a Lei de Diretrizes e Bases da Educação Nacional (LDBEN) no 9.394 (Brasil, 1996) dedica um capítulo inteiro à Educação Especial (Capítulo V), definindo-a como uma modalidade de educação escolar que deve ser oferecida, preferencialmente, na rede regular de ensino, pois reconhece o caráter de excepcionalidade de algumas situações muito particulares. Essa lei traz avanços significativos em relação à Lei de Diretrizes e Bases anterior, pois não deixa mais dúvidas quanto ao princípio de que a Educação Especial deve estar enquadrada no sistema regular de ensino.

No início dos anos 2000, através do Decreto no 3.956 (Brasil, 2001), foi promulgada a convenção interamericana para a eliminação de todas as formas de discriminação contra as pessoas com deficiência, donde se reafirma que essas pessoas, assim como todas as outras, têm direitos humanos e liberdades fundamentais garantidas. Esse documento foi de grande importância para a área educacional, pois promoveu a eliminação de qualquer barreira legislativa que impedisse ou dificultasse o acesso do aluno com deficiência à escolarização.

Com base nessas premissas, pode-se afirmar que, nos últimos 50 anos, a Educação Especial no Brasil tem sido marcada por mudanças significativas e que, apesar de permanecerem algumas possibilidades de manutenção do ensino segregado de alunos com deficiência, as políticas postas em prática têm-se constituído, de forma gradual, em mecanismos que colaboram para o fortalecimento da educação numa dimensão inclusiva.

No entanto, apesar dos significativos avanços pelos quais tem passado a legislação brasileira, Gonçalves et al. (2013) indicam que, entre 2007 e 2010, para os jovens e adultos com deficiência, ainda predomina a matrícula em escolas ou classes especiais, embora tenha havido um movimento crescente de inclusão de alunos com deficiência no sistema de ensino regular 
do país. Para Siems (2011), esse aumento deve-se, entre outros fatores, à transferência de alunos das instituições especiais, classes especiais e escolas especiais para as salas do ensino regular, como também reflete uma dinâmica mais efetiva de conscientização e de atuação dos movimentos sociais, com vistas a assegurar o acesso de pessoas com deficiência no sistema regular de ensino.

Uma ação em prol desse movimento foi determinada pela Resolução do Conselho Nacional de Educação (CNE) e da Câmara de Educação Básica (CEB) no 4 (Brasil, 2009), que resolveu, no Artigo 2ํㅡㄹ caracterizar, por meio do Atendimento Educacional Especializado (AEE), a responsabilidade das escolas em oferecer meios e recursos necessários para que os alunos com deficiência possam avançar educacionalmente.

Essa resolução pode ser considerada preambular, pois se constitui em um grande desafio para o governo no que concerne a preparar as escolas, tanto em relação aos recursos físicos quanto humanos, para acolher, ensinar e apoiar os alunos com deficiência, visto que o Brasil é um país com dimensões continentais, que abriga um grande contingente de escolas públicas.

A questão que ecoa a partir desse contexto diz respeito à efetivação de oportunidades educacionais de qualidade para as pessoas com deficiência, a partir das políticas de inclusão escolar. Ensejando aprofundar a temática, este estudo tem por objetivo conhecer o processo de inclusão de jovens e adultos com deficiência na escola regular noturna do Ceará, recorrendo à pesquisa documental de fontes primárias como método de investigação, com foco nas políticas públicas que regem o processo de inclusão desses jovens.

Para atender ao objetivo proposto, este trabalho parte de uma imersão em documentos produzidos pelos órgãos deliberativos da educação no Ceará, que englobam as resoluções do Conselho Estadual de Educação (CEE), que regulam a Educação de Jovens e Adultos (EJA) e a educação inclusiva no Estado, e os Projetos Políticos Pedagógicos (PPP) das escolas definidas para a pesquisa.

\section{Método}

O método de investigação deste estudo baseia-se na pesquisa documental de fontes primárias, numa abordagem qualitativa, por ser um método de investigação da realidade social, que não traz em seu bojo uma única concepção filosófica de pesquisa, podendo ser empregada tanto nas abordagens de natureza positivista quanto nas abordagens de natureza compreensiva (Silva et al., 2011). A concepção filosófica da pesquisa tem caráter compreensivo, com enfoque mais crítico, dando ênfase à importância das informações que se pretende obter, a partir de um 
olhar criterioso e perscrutador das fontes documentais, selecionadas com base nos interesses da investigação.

Diante do exposto, assegura-se a opção do método de investigação definido e seu uso, neste estudo, por ser um dos caminhos adequados para desvelar os rumos da inclusão de jovens e adultos com deficiência no ensino regular do estado do Ceará, considerando a natureza exploratória do objeto de estudo. O problema de pesquisa, por sua vez, foi assim estabelecido: Como está normatizada a inclusão de jovens e adultos no ensino regular cearense, à luz dos documentos que estabelecem os parâmetros de organização desse segmento educacional?

Este estudo teve como cenário de pesquisa as escolas públicas estaduais de ensino regular do município de Fortaleza, estado do Ceará - Brasil, pertencentes à Secretaria Executiva Regional (SER) VI. Para uma melhor compreensão do universo investigado, informa-se que as escolas públicas estaduais de ensino regular de Fortaleza pertencem à Superintendência das Escolas Estaduais de Fortaleza (SEFOR) e totalizavam, à época da pesquisa, 174 unidades, divididas administrativamente em seis SER, das quais 31 compunham a SER VI. A opção por essas escolas foi uma decisão da pesquisadora, por contemplarem as características necessárias à objetivação do estudo. Nem todas as escolas da SER VI participaram da pesquisa, pois só estavam elegíveis as que tinham turmas de EJA, e somente 11 das 31 escolas possuíam tal modalidade.

\section{Procedimentos}

A primeira tarefa desenvolvida foi a pré-análise, cujo objetivo era delimitar fontes e, nelas, os documentos necessários à pesquisa. Concluída a pré-análise, passou-se à leitura de todos os documentos, com o intuito de selecionar aqueles cujo tema estava diretamente relacionado ao objeto de estudo. A seguir, passou-se a uma segunda leitura, com o intuito de averiguar a veracidade e credibilidade dos documentos selecionados, bem como a adequação às exigências da pesquisa (Calado e Ferreira, 2004). Tal avaliação foi feita à luz das orientações dadas por Cellard (2008), que sugere cinco dimensões para se avaliar preliminarmente os documentos: contexto, autor, autenticidade e confiabilidade, natureza do texto, conceitos-chave e lógica interna.

Após a confirmação da autenticidade e credibilidade dos documentos, passou-se à fase de organização do material, que exigiu um olhar analítico sobre o conjunto da obra. Nessa fase, tendo as leituras e os fichamentos como papel central, foi criado um documento-síntese, com vistas a possibilitar uma maior compreensão do processo de organização do material analisado. 


\section{Análise de dados}

Para a análise dos dados recolhidos, adotou-se a análise de conteúdo, fundamentada teoricamente em Bardin (2016). A primeira ação desenvolvida envolveu a leitura flutuante do corpus, com vistas a estabelecer os contornos das unidades de análise, quais sejam: as unidades de registro e as de contexto. Para a identificação das unidades de contexto foi dada uma atenção específica ao contexto de influência e ao contexto de produção dos documentos. A seguir, passou-se à identificação das unidades de registro, que teve como foco os temas desenvolvidos nos documentos.

Com base na frequência com que os temas apareceram nos documentos, assim como em sua relevância implícita, definiram-se três categorias de análise, a saber: 1. Mapeamento da inclusão - Quantos e quem são os jovens e adultos com deficiência matriculados na EJA do Ceará; 2. Currículo e inclusão - Que adequações curriculares são propostas para a educação inclusiva nos documentos analisados; 3. Profissionais da educação e inclusão - Como os profissionais são preparados para trabalhar com a inclusão.

A construção dessas categorias teve como fundamento a abrangência, de forma a permitir a inclusão de todos os dados; a objetividade e a possibilidade de fornecerem resultados férteis.

\section{Resultados e Discussão}

Para proceder à apresentação dos resultados e discussão do estudo, tomou-se por base um horizonte temporal de aproximadamente 20 anos, iniciando com a promulgação da LDBEN no 9.394 (Brasil, 1996) até os dias atuais. Esse marco temporal não é uma escolha aleatória, e sim a marcação de um tempo em que a discussão sobre a inclusão na esfera pública toma novos rumos, no país, à luz do cenário mundial, cujo processo já estava mais avançado, considerando as ações ocorridas nos Estados Unidos nos anos 1970 e na Europa nos anos 1980 e 1990, que passam a defender a inclusão em larga escala, e focou-se nas proposições das políticas estaduais para a educação de jovens e adultos na esfera pública cearense, a partir das categorias anteriormente especificadas.

Em relação ao mapeamento da inclusão da EJA no Ceará, a normatização foi fixada através da Resolução CEE no 436 (Brasil, 2012), que estabeleceu normas para a Educação Especial e para o Atendimento Educacional Especializado no âmbito do sistema de ensino do Estado. Nesta, a Educação Especial, definida como modalidade transversal a todos os níveis e modalidades de ensino, passou a fazer parte integrante do ensino regular, devendo ser contemplada no projeto pedagógico das unidades escolares. No mesmo documento, também foi definido o público-alvo 
da Educação Especial: os alunos com altas habilidades/superdotação; os alunos com impedimentos de longo prazo de natureza física, intelectual, mental ou sensorial e os alunos com transtornos globais do desenvolvimento, incluindo-se os alunos com autismo, síndrome de Asperger, síndrome de Rett, transtorno desintegrativo da infância e transtornos invasivos sem outra especificação. Em 2016, a Resolução CEE no 456 (Brasil, 2016) reestruturou este último grupo, especificando que os alunos com Transtornos Globais de Desenvolvimento (TGD) são aqueles que apresentam um quadro de alterações no desenvolvimento neuropsicomotor, comprometimento nas relações sociais, na comunicação ou estereotipias motoras, incluindo-se nessa definição alunos com autismo clássico, autismo de alto desempenho ou síndrome de Asperger, e transtornos invasivos sem outra especificação. É importante ressaltar que essa reestruturação não está de acordo com o Manual Diagnóstico e Estatístico de Transtornos Mentais: DSM-5 (American Psychiatric Association, 2014).

Um dado importante observado ao se analisar o projeto político das escolas participantes da pesquisa foi a constatação de que somente em três dos onze projetos analisados, o atendimento ao aluno com deficiência foi contemplado. Esse número é, significativamente, reduzido e sinaliza uma falta de visibilidade das instituições em relação ao grupo de alunos em estudo. É importante ressaltar que não se pode pensar na ação de colocar o aluno na escola como o ato mais significativo do processo de inclusão, pois sua significância só se completa se houver um movimento em prol do desenvolvimento de práticas que fomentem a participação dos alunos em atividades do cotidiano, nas dimensões física, funcional, social e comunitária. Há que se considerar também a importância do percurso formativo dos alunos, independente de serem alunos com deficiência ou não, pois como afirmam Duarte et al. (2020, p. 122), há "diferenças significativas nas dimensões da adaptabilidade de carreira em função do tipo de percurso educativo".

Quanto às adequações curriculares propostas para a educação inclusiva, dois enfoques precisam ser considerados: o que se refere aos sistemas de ensino e o que se refere às instituições escolares. Em relação aos sistemas de ensino, os indicadores que thes são mais específicos estão relacionados às diretrizes legais, organização e gestão de cada sistema, financiamento da educação e condições de trabalho dos educadores. Em relação às instituições escolares, os indicadores focamm na gestão da aprendizagem, no redimensionamento e na transformação da escola.

Tomando por base as normativas legais, a LDBEN no 9.394 (Brasil, 1996) estabelece ser responsabilidade dos sistemas de ensino: assegurar aos educandos com necessidades especiais 
os currículos, métodos, técnicas, recursos educativos e organização específicos para atender às suas necessidades. Por sua vez, a Resolução CNE/CEB no 2 (Brasil, 2001) referenda que a organização e a operacionalização dos currículos escolares são de competência e responsabilidade dos estabelecimentos de ensino, respeitando as diretrizes curriculares nacionais da Educação Básica, devendo constar dos projetos políticos pedagógicos das escolas.

Dentro desse raciocínio, os Parâmetros Curriculares Nacionais (PCN), produzidos a partir de 1997 pelo MEC e pela Secretaria de Educação Fundamental (SEF), com o intuito de nortear o trabalho docente quanto à definição das propostas curriculares para cada nível e quanto à forma como os conteúdos devem ser abordados, destaca que a educação dos alunos com deficiência deve contemplar as "diferenças individuais" (SEF, 1997, p. 18) e "requerer um tratamento diversificado dentro do mesmo currículo" (SEF, 1997, p. 24). O Ceará, nesse contexto, normatiza, por meio das Resoluções CEE no 436 (Brasil, 2012) e no 456 (Brasil, 2016), que fixam normas para a Educação Especial, que o currículo para atender aos alunos com deficiência deve ser o mesmo oferecido aos demais alunos, respeitando-lhes os ritmos e interesses de aprendizagem. A verificação do rendimento escolar, por sua vez, levará em conta a evolução do aluno no processo e os aspectos básicos de socialização.

Para melhor compreensão dessa assertiva sobre o currículo, cumpre entender qual o currículo oferecido aos alunos da EJA. A Resolução CEE no 363 (2000), que dispõe sobre a educação de jovens e adultos, elenca um rol de capacidades a serem desenvolvidas na EJA, que envolvem dominar os elementos básicos da cultura letrada, valorizar a diversidade cultural brasileira, valorizar a educação como meio de desenvolvimento pessoal e social, desenvolver atitudes de participação cidadã, entre outras, por meio de técnicas que priorizem atividades em grupo, de cunho interdisciplinar, e que enfatizem a leitura com significado, assim como a solução de problemas.

A Resolução CEE no 438 (Brasil, 2012), que também dispõe sobre a educação de jovens e adultos, numa versão mais atualizada, preceitua a aprendizagem autônoma para desenvolver as mesmas capacidades anteriormente mencionadas e prevê flexibilidade, tanto para o currículo quanto para a gestão de tempo e espaço, com vistas a uma aprendizagem significativa para o público adulto. Nessa resolução, a identidade cultural e os saberes experienciais dos alunos são amplamente considerados e lhes é dada mais autonomia para gerir a aprendizagem, numa dimensão de superação da disciplinaridade. Também é dada uma ênfase às formas de inserção na cultura digital, como caminho para desenvolver a pesquisa e a produção de novos conhecimentos. 
Todas essas normatizações não deixam claro como superar a questão posta, de oferecer aos alunos com deficiência um currículo mais flexível em um espaço de tempo maior, ficando subjacente que os caminhos a serem desbravados são de responsabilidade das instituições e, por extensão, dos professores.

Na categoria que trata da formação de professores para a inclusão, o Artigo 62 da LDBEN no 9.394 (Brasil, 1996) define que a formação do professor da Educação Básica deve ser de nível superior, em curso de licenciatura de graduação plena, podendo ser de nível médio, na modalidade Normal se for para o exercício do magistério na Educação Infantil ou na primeira fase do Ensino Fundamental. Para atender aos alunos com deficiência, a Lei assegura, por meio dos sistemas de ensino, professores do ensino regular capacitados e professores com especialização adequada em nível médio ou superior, para atendimento especializado. Ou seja, de acordo com a LDBEN no 9.394 , a Educação Especial na Educação Básica admite dois perfis de professores: os que são capacitados e os que são especializados, devendo atuar em equipe, inclusive com professores especializados na área (Brasil, 2001: Resolução CNE/CEB no 2) e desenvolver um trabalho colaborativo que possibilite articular as atividades do ensino regular com as do AEE (Brasil, 2009: Resolução CNE/CEB no 4,).

A diferença entre capacitação e especialização está estabelecida na Resolução CNE/CEB no 2 (Brasil, 2001). Nesta Resolução, a capacitação pressupõe que a formação do professor contemple "conteúdos sobre educação especial" que estejam correlacionados com a inclusão escolar sem, no entanto, especificar a natureza da formação, a carga horária mínima ou a modalidade, permitindo uma diversidade grande de possibilidades. Tal proposição pode resultar em professores com níveis diferentes de formação para a mesma função e pode, ainda, permitir uma possível redução no grau de exigência da capacitação. Uma alternativa para suplantar tal possibilidade seria a inserção do conteúdo referente à inclusão nos cursos de Pedagogia e nas demais licenciaturas, que já foi tentada como recomendação do MEC em 1994. Entretanto, o fato é que muitos cursos não aderiram a tal recomendação, e continuam sem apresentar em seu currículo conteúdos especificamente relacionados à inclusão escolar (Rinaldi et al., 2007) ou, quando o fazem, refletem uma forte influência do modelo médico-psicológico, que rotula os alunos e os classifica de acordo com uma abordagem meramente técnica (Omote, 2004). A especialização, por sua vez, pressupõe que a formação do professor se dê por meio de licenciatura em Educação Especial ou em uma de suas áreas, ou ainda por meio de pósgraduação em áreas específicas. São também considerados especializados os professores "intérprete das linguagens e códigos aplicáveis", ou seja, aqueles que trabalham com Libras, 
Braille ou outros sistemas alternativos de comunicação. O professor especializado é aquele que presta o AEE nas salas de recursos ou em estabelecimentos especiais de ensino e possui uma formação específica. A política em vigor, evidenciada pela Resolução CNE/CEB no 4 (Brasil, 2009), projeta que esses professores, embora tenham uma formação centrada nas deficiências, sejam capazes de trabalhar com todos os tipos de deficiência, ou seja, prevê um professor que atue com todas as categorias de deficiência, transtornos globais do desenvolvimento e altas habilidades ou superdotação.

As Resoluções CEE № 436 (Brasil, 2012) e no 456 (Brasil, 2016), ao tratar da formação de professores para a Educação Especial, confirmam o que está estabelecido na LDBEN no 9.394 (Brasil, 1996) e nas diretrizes curriculares nacionais para a formação docente. Um acréscimo é o estabelecimento da carga horária mínima de 180 horas para os cursos de especialização e/ou aperfeiçoamento em educação inclusiva, oferecidos aos professores da rede.

Um segundo aspecto a ser analisado sobre a formação dos professores capacitados e especializados para trabalhar com a inclusão diz respeito às competências que se esperam deles. De acordo com o expresso na Resolução CNE/CEB no 2 (Brasil, 2001), espera-se que os professores capacitados estejam aptos a perceber as necessidades educacionais especiais, flexibilizar a ação pedagógica e avaliar a eficácia do processo. Em relação aos professores especializados, a expectativa é maior, e deles espera-se que identifiquem as necessidades educacionais especiais; definam, programem, liderem e apoiem a implementação de estratégias de flexibilização da ação pedagógica e deem assistência aos professores capacitados. De ambos é esperado que trabalhem em equipe.

Com base nessas premissas, é possível estabelecer que a atual política de formação para a Educação Especial na Educação Básica coloca os professores capacitados e especializados num patamar hierárquico, tanto em relação ao processo de formação quanto em relação às competências, onde o professor especializado é o supervisor e o professor capacitado é o executor. Embora seja esperado de ambos que trabalhem em equipe, fica subjacente a possibilidade de que disputem entre si por espaço e autoridade. Essa questão leva a outra reflexão, qual seja: a de que a relação hierárquica na ação docente pode gerar um processo de controle do trabalho dos professores a partir de indicadores de resultado, o que não seria justo com o professor, visto que a forma como a escola regular está organizada não favorece o pleno desenvolvimento de todos os alunos, ainda mais numa dimensão inclusiva.

Outra questão importante a ser analisada diz respeito ao conteúdo das formações. Tomando-se por base a experiência do Ceará, há um direcionamento para cursos que abordam 
as dificuldades específicas de um ou outro tipo de deficiência, mas falta um direcionamento para formações que tratem dos processos de ensinar e aprender, pois a ação pedagógica com jovens, sejam eles deficientes ou não, envolve muitos outros elementos, que precisam ser conhecidos e discutidos, assim como um melhor nível de formação acadêmica tende a propiciair aos professores melhores níveis de inteligência emocional (Valente, 2019). Esses elementos deveriam estar contemplados nos Projetos Políticos Pedagógicos das escolas, mas o que se constata, ao analisar os documentos do corpus deste estudo, é que a formação docente não está contemplada em todos os projetos (o tema só é tratado em $64 \%$ dos projetos) e que, quando tratada, aparece em forma de objetivo estratégico, com uma abordagem bem geral ou como meta a ser atingida em relação ao quantitativo de professores a serem capacitados.

Em relação aos professores da EJA, há ainda uma questão que dificulta o processo de formação: o horário em que acontecem. Normalmente, essas atividades ocorrem no turno diurno, quando os professores estão comprometidos com outras atividades acadêmicas que não Ihes permitem participar dos cursos.

De todo o exposto, constata-se que a inclusão educacional envolve muito mais que a garantia de os alunos com deficiência estarem nas salas de aula regulares, visto que abrange a articulação dos diferentes setores relacionados com a efetivação da educação inclusiva, a formação do professor para lidar com as diferenças presentes na sala de aula, a valorização da tecnologia assistiva como subsídio para a aprendizagem daqueles que têm dificuldade em aprender pelos meios convencionais, ou seja, implica uma ação conjunta, que possibilite a construção de novos patamares educacionais.

\section{Conclusão}

O acesso à educação no Brasil é direito garantido a todos os cidadãos. No caso da inclusão de pessoas com deficiência na esfera educacional, o tema tem sido tratado com maior ênfase no final dos anos 1990, tendo sido contemplado no Plano Decenal de Educação para Todos, em 1993, elaborado em cumprimento às resoluções da Conferência de Jomtien, em 1990, que tinha como meta recuperar a escola fundamental no país. Esse documento foi consolidado na LDBEN no 9.394 (Brasil, 1996) e, em 2014, o tema foi referendado no Plano Nacional de Educação (Brasil, 2014: Lei no 13.005).

Nesse processo discursivo, várias proposições foram observadas: a universalização dos direitos humanos, a democratização da educação, o exercício pleno da cidadania, a valorização da diversidade e a constatação de que a diferença existe e não pode continuar sendo relegada 
à marginalidade. A escola passou a ser lócus de inclusão e, por conseguinte, sua reestruturação foi propagada como forma de atender a todos os alunos, indistintamente. Tal proposição reflete o campo fértil que a inclusão encontra na política educacional brasileira, mas tem-se mostrado difícil de ser concretizada, visto que as instituições educativas, salvo raras exceções, não estão preparadas para incluir os alunos com deficiência.

As leituras e análises realizadas possibilitaram verificar que a inclusão é parte integrante dos discursos relacionados à educação na dimensão normativa do Estado, mas que esses discursos não estão presentes nos projetos das instituições escolares com a mesma força. Outra constatação diz respeito ao quantitativo de alunos com deficiência que estão ingressando na escola regular. Esse número vem aumentando, paulatinamente, nos últimos cinco anos; contudo, tornou-se importante compreender a qualidade do trabalho desenvolvido nas escolas para atender esse público, tomando como recorte a formação de professores, pois a tentativa de modificar alguns aspectos da prática pedagógica tem-se revelado uma forma superficial e ineficaz de promover a inclusão, se os professores continuarem a considerar que a deficiência é uma incapacidade fixa e definitiva (Ainscow e Miles, 2016).

Com base nas reflexões desenvolvidas, pode-se afirmar que as políticas de inclusão do Ceará acompanham o que está proposto na política nacional. No entanto, há uma tendência a deixar o gerenciamento das ações a cargo das unidades escolares, o que não favorece uma participação mais ampla da sociedade, que poderia traduzir-se em melhores frutos tanto no que concerne à qualidade do trabalho pedagógico direcionado aos alunos com deficiência, quanto em relação à sua inserção social na escola e nos demais equipamentos culturais.

Articula-se a essa afirmação o não dito nos projetos pedagógicos das instituições escolares em relação ao trabalho com a inclusão. Tal omissão pode sinalizar um reconhecimento da deficiência como algo minoritário, que não precisa ser contemplado, ou ainda uma falta de condições estruturais e pedagógicas para atender às diferenças individuais postas pela inclusão. Há, no entanto, mesmo que nas entrelinhas dos projetos, um discurso politicamente correto, que remete à igualdade de oportunidades, ao respeito à individualidade, à formação cidadã, ao não preconceito.

Reconhece-se como limitações a impossibilidade de abordar a totalidade da metodologia de trabalho com os diversos tipos de documentos disponibilizados, donde priorizou-se o texto escrito ou impresso. Como proposta de pesquisas futuras, evidencia-se a necessidade de ampliar a perspectiva metodológica, delineada neste artigo, com a inserção de documentos oriundos de outras fontes e com outras tipologias. Quanto a este estudo, destacam-se como contribuições: 
ampliar a discussão sobre a inclusão de alunos com deficiência na EJA e mostrar, empiricamente, o que está posto na legislação e nas pesquisas recentes sobre o tema no Ceará. Tais contribuições permitem uma visão do contexto da escola pública e da realidade da EJA no Ceará, e abre espaço para que novas pesquisas sejam desenvolvidas, tomando por base os resultados obtidos.

\section{Referências}

AINSCOW, Mel; MILES, Susie (2016). Education for all. Ainscow, M. Struggles for Equity in Education London: Routlegde

AMERICAN PSYCHIATRIC ASSOCIATION (2014). Manual diagnóstico e estatístico de transtornos mentais: DSM-5 (tradução: M. I. C. Nascimento.). Porto Alegre, Artmed. [Versão original: 2013, Autor. https://doi.org/10.1176/appi.books.9780890425596]

BARDIN, Laurence (2016). Análise de conteúdo (L. A. Reto e A. Pinheiro, Trads.) (3a reimp. da 1a ed.). Lisboa: Edições 70.

BRASIL (1988). Constituição da República Federativa do Brasil de 1988. www.planalto.gov.br/ ccivil_03/constituicao/constituicao compilado.htm

BRASIL (1996). Lei no 9.394, de 20 de dezembro de 1996. Estabelece as diretrizes e bases da educação nacional. http://www.planalto.gov.br/ccivil_03/LEIS/L9394.htm

BRASIL (2000). Resolução no 363, de 11 de outubro de 2000. Dispõe sobre a educação de jovens e adultos. https://www.cee.ce.gov.br/legislacao/resolucoes/resolucoes-do-conselhoestadual/resolucoes-da-camara-de-educacao-basica/

BRASIL (2001). Decreto no 3.956, de 8 de outubro de 2001. Promulga a Convenção Interamericana para a Eliminação de Todas as Formas de Discriminação contra as Pessoas Portadoras de Deficiência. http://www.planalto.gov.br/ccivil_03/decreto/2001 /d3956.htm

BRASIL (2001). Resolução no 2, de 11 de setembro de 2001. Institui diretrizes nacionais para a educação especial na educação básica. http://portal.mec.gov.br/index.php?option= com_content\&view=article\&id=13201:resolucao-ceb-2001\&catid=323:orgaosvinculados

BRASIL (2009). Resolução no 4, de 2 de outubro de 2009. Institui diretrizes operacionais para o atendimento educacional especializado na educação básica. http://portal.mec.gov.br/ index.php?option=com_content\&view=article\&id=13684:resolucoes-ceb-2009\&catid= 323:orgaos-vinculados 
BRASIL (2012). Resolução no 436, de 29 de fevereiro de 2012. Fixa normas para a educação especial e para o atendimento educacional especializado. https://www.cee.ce.gov.br/legislacao/ resolucoes/resolucoes-do-conselho-estadual/resolucoes-da-camara-de-educacao-basica/

BRASIL (2012). Resolução no 438, de 25 de abril de 2012. Dispõe sobre a educação de jovens e adultos. https://www.cee.ce.gov.br/legislacao/resolucoes/resolucoes-do-conselho-estadual /resolucoes-da-camara-de-educacao-basica/

BRASIL (2014). Lei no 13.005, de 25 de junho de 2014. Aprova o Plano Nacional de Educação (PNE) e dá outras providências. http://www2.camara.leg.br/legin/fed/lei/2014/lei13005-25-junho-2014-778970-publicacaooriginal-144468-pl.html

BRASIL (2016). Resolução no 456, de 1ำ de junho de 2016. Fixa normas para a educação especial e para o atendimento educacional especializado. https://www.cee.ce.gov.br/legislacao/ resolucoes/resolucoes-do-conselho-estadual/resolucoes-da-camara-de-educacao-basica/

BRASIL (2020a). Censo da Educação Básica 2019: Resumo Técnico. Brasília: Instituto Nacional de Estudos e Pesquisas Educacionais Anísio Teixeira (INEP). Disponível em: http://portal. inep.gov.br/informacao-da-publicacao/-/asset_publisher/6JYIsGMAMkW1/document/ id/6874720

BRASIL (2020b). Resumo Técnico: Censo da Educação Básica Estadual 2019 [recurso eletrônico]. Brasília: Instituto Nacional de Estudos e Pesquisas Educacionais Anísio Teixeira (INEP). Disponível em: https://www.gov.br/inep/pt-br/centrais-de-conteudo/acervo-linhaeditorial/publicacoes-institucionais/estatisticas-e-indicadores-educacionais/resumotecnico-do-estado-do-ceara-2013-censo-da-educacao-basica-2019

CALADO, Silvia dos Santos; FERREIRA, Silvia Cristina (2004). Análise de documentos: método de recolha e análise de dados. Metodologia da Investigação I-2004/2005, 1-13.

CELLARD, André (2008). A análise documental. In J. Poupart et al., A pesquisa qualitativa: enfoques epistemológicos e metodológicos (A.C. Nasser, Trad.) (pp. 295-316). Petrópolis: Vozes.

DUARTE, Francisca da Conceição; PAIXÃO, Maria Paula; SILVA, José Tomás da (2020). Diferenças na adaptabilidade da carreira em dois momentos do ensino secundário. Revista de Estudios e Investigación en Psicología y Educación, 7(2), 115-126. https://doi.org/10. 17979/reipe.2020.7.2.6420

GONÇALVES, Taísa Graziela G. L.; BUENO, José Geraldo S.; MELETTI, Silvia Marcia F (2013). Matrículas de alunos com deficiência na EJA: uma análise dos indicadores educacionais brasileiros. Revista Brasileira de Política e Administração da Educação, 29, 407-427. https://doi.org/10.21573/vol29n32013.47212 
MANTOAN, Maria Teresa E (2015). Inclusão escolar - O que é? Por quê? Como fazer? São Paulo: Summus Editorial.

MANTOAN, Maria Teresa E.; SANTOS, Maria Terezinha C. T. S (2010). O atendimento educacional especializado: políticas e gestão nos municípios. São Paulo: Moderna.

OMOTE, Sadao (2004). Estigma no tempo da inclusão. Revista Brasileira de Educação Especial, 10(3), 287-308. Marília: Fundepe Editora.

ORRÚ, Silvia Ester (2017). O re-inventar da inclusão: os desafios da diferença no processo de ensinar e aprender. Petrópolis: Vozes.

PLETSCH, Marcia Denise (2014). Repensando a inclusão escolar: diretrizes políticas, práticas curriculares e deficiência intelectual (2a ed.). Rio de Janeiro: Nau Editora.

RINALDI, Renata. P.; REALI, Aline Maria M. R.; COSTA, Maria Piedade R (2007). Educação especial e formação de professores: onde estamos... para onde vamos? Horizontes 25(1), 87-98.

ROHLING, Marcos; VALLE, Ione R (2016). Princípios de justiça e justiça escolar: a educação multicultural e a equidade. Cadernos de Pesquisa, 46(160), 386-409. https://doi.org/ $10.1590 / 198053143287$

Secretaria de Educação Fundamental - SEF (1997). Introdução aos parâmetros curriculares nacionais - livro 1. Brasília: Autor.

SIEMS, Maria Edith R (2011). Educação de jovens e adultos com deficiência: saberes e caminhos em construção. Educação em Foco, 16, 61-80.

SILVA, Lidiane R. C.; DAMASCENO, Ana Daniella; MARTINS, Maria Conceição R.; SOBRAL, Karine M.; FARIAS, Isabel Maria S (2011). Pesquisa documental: caracterização e interface na produção acadêmica em Educação. In S. M. № Therrien; I. M. S. Farias; J. B. C. Nunes (Orgs.), Pesquisa científica para iniciantes: caminhando no labirinto, 3 (pp. 55-66). Fortaleza: EdUECE.

VALENTE, Sabina (2019). Influência da inteligência emocional na gestão de conflito na relação professor-aluno(s). Revista de Estudios e Investigación en Psicología y Educación, 6(2), 101-113. https://doi.org/10.17979/reipe.2019.6.2.5786

Fecha de recepción: 18 de marzo de 2021.

Fecha de revisión: 3 de junio de 2021. Fecha de aceptación: 6 de junio de 2021. Fecha de publicación: 1 de julio de 2021. 